\title{
Auto Metro Train to Shuttle between Stations using Arduino
}

\author{
S V S Prasd, K Nishanth Rao, V Arun, D Laxma Reddy
}

\begin{abstract}
This Paper Encapsulates About The Technology Used In Driverless Trains Which Are Furnished With A Control System. There Are Many Cases To Avoid Accidents While Driving Due To Human Faults, This Paper Is Implemented To Provide The Station Information Such As Path, Arrival And Departure Timings Of A Train. Distance Between Stations Is All Pre-Defined Relevantly To The Passengers With Announcement And Displays A Message On Screen Including The Passenger Occupancy Count In Train. This Metro Train Consists Of Controller That Operates The Train To Run From One Station To Another Station. After Train Reaches The Destination, The Process Will Be Continued For Further Stations.
\end{abstract}

Keywords: Arduinoatmega 2560, Ir Sensor, Flame Sensor, Audio Recorder Module.

\section{INTRODUCTION}

Modern Technology has developed a lot in all aspects of our life including transportation where a huge transformation has undergone[1]. Even though, the accidents of trains are increasing day by day. Main cause of accidents and crashes are due to human errors and more than half of the people's death is due to accidents. To prevent this problem we have introduced a prototype of auto metro train where human interruption is not required. The objective of this paper is to drive the train automatically. This paper is implemented in many countries like France, Germany, etc. This paper main aim is to represent the technology used in shuttling metro train between stations. But considering present days the accidents rate has increased day by day, of these disasters are occurring due to human irregularity and irresponsibility. Processor doesn't have a probability of doing errors but a man can do a mistake. The controlof a train depends on the arduino programming [2,9].Considering the safety of passengers we had used a flame sensor, whenever causing a fire accident it gives a signal to the passengers.Due to the human errors many accidents occur. In electric trains fault occurring chances are more. Metro Train is an integrated application which displays and announces the station names when it reaches a particular station. The existing system can have more chances to get miscommunication with the passengers while announcement.

Revised Manuscript Received on December 30, 2019.

* Correspondence Author

S V S Prasd, Department Of Electronics And Communication Engineering Mlr Institute Of Technology, Hyderabad

K Nishanth Rao, Department Of Electronics And Communication Engineering Mlr Institute Of Technology, Hyderabad

V Arun, Department Of Electronics And Communication Engineering Mlr Institute Of Technology, Hyderabad

D Laxma Reddy, Department Of Electronics And Communication Engineering Mlr Institute Of Technology, Hyderabad

(C) The Authors. Published by Blue Eyes Intelligence Engineering and Sciences Publication (BEIESP). This is an open access article under the CC BY-NC-ND license (http://creativecommons.org/licenses/by-nc-nd/4.0/)
This process of miscommunication may lead to wrong allocation for the trains, and train collision occurs. More man power is required to perform operations. Installation and integration is time taken process.

\section{METHODOLOGY}

Proposed system extends the prototype by adding eminent features and decreasing the human interference[3] as the train is operated automatically. After the prescribed time the doors will be opened and shuttled[4] to the next station by closing the door. There is a limit to passengers count not to occur disputes among passengers. Flame sensors are used for the protection of passengers.

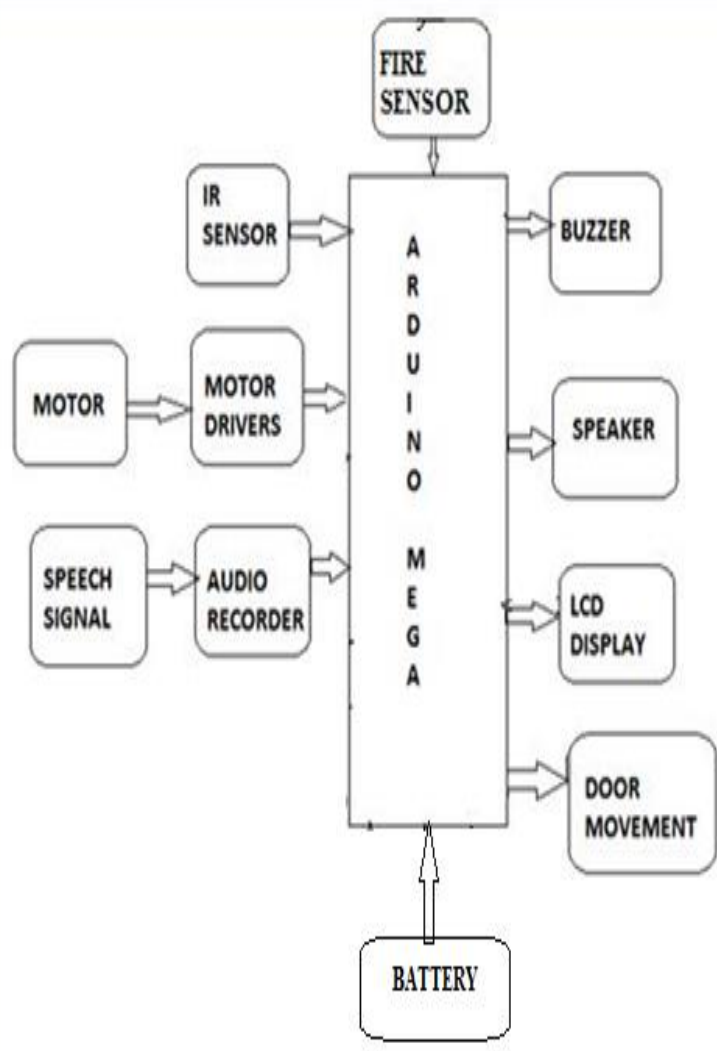

Fig-1: Block Diagram of Auto metro train

TheFig1 shows[5] the detailed working about this prototype.

- Initially when the train starts, it moves automatically with the help of motors which consists of motor drivers to run in forward direction.

- By using the limit switch we can identify whether the door is opened or closed. 
- The messages can be observed in LCD screen.

- Persons count will be observed whenever the passenger passes through IR sensors.

- If first IR sensor is high it means the person is entering into the train.

- If second IR sensor is high, then the person is leaving the train.

- Audio Recorder helps to announce the station names using speaker which are pre-defined in module.

- If flame sensor is ON, then door opens and it gives a buzzer sound to alert the passengers.

- If the train left with no more seats then it also reduces overpopulation inside the train.

Train starts automatically and when it arrives the station it stops informingly, then the door opens and closes so that the passengers can go inside the train until a prescribed time set in the controller, when it reaches a particular station it stops for a certain time limit which is pre-programmed and then shuttles to the other station. It is also equipped with a passenger counting section, which counts the number of passengers entering and leaving the train. By using IR Sensor, the number of persons who are coming inside will be counted at the same time it will reduce the count when the passenger leaves the train. . It displays increment and decrement of passengers count in LCD[6]. Then the door closes automatically when it reaches maximum occupancy of seats. Alarm signals are produced when there is a chance of fire accidents circumstances. Apart from giving a buzzer to alert the passengers it also opens the door automatically.

This model has implemented to provide security[7], consistent, efficiency and high- quality service to the passengers. Thistype of automated trains[8] can be inserted in traffic without the help of human operations can be performed so that traffic levels will be reduced.This should be high equipped to identify the safety systems like fire accidents, noticing if any possible damage in the track.

\section{RESULT}

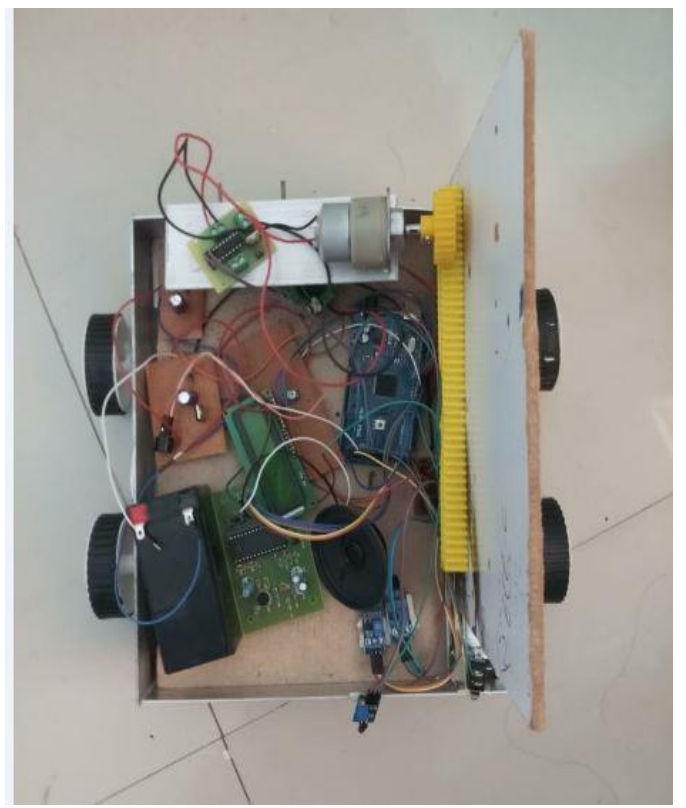

Fig 2: Final Prototype

The Fig 2 is a robotic train which is controlled by an Arduino. If the train reaches a particular station it stops automatically, it announces and displays the station name. Then the door opens for entering the passengers which will be counted by using IR sensors. There is a count limit of 20 people to enter into the train and fill the seats in this prototype. Once the limit exceeds it doesn't opens the door. After time limit the train starts moving to other station and this process is repeated. The train incorporates a buzzer to alert the passengers while causes a fire accidents.

This prototype will work perfectly when it has maximum power supply that should be transformed to each and every individual required component in train.

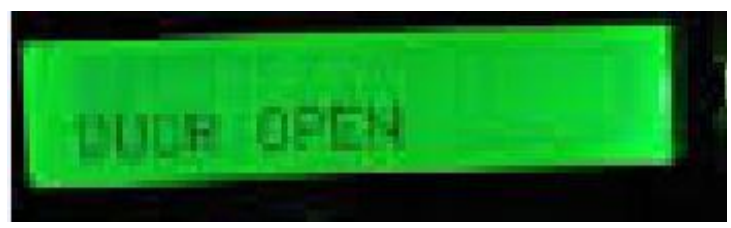

(a)

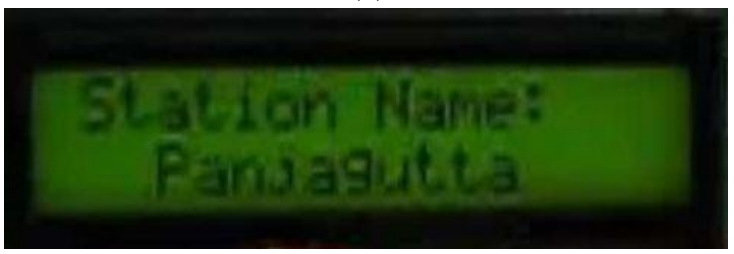

(b)

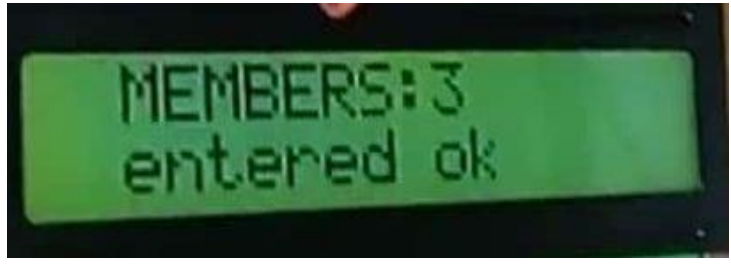

(c)

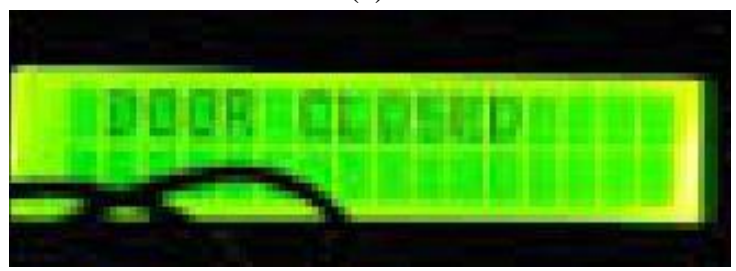

(d)

Fig 3: LCD Screen message

When the train reaches a particular station it opens the door and displays a message "DOOR OPENS" in LCD screen as we can observe it in Fig (a). Then the passengers can get inside the train after the door opening.

After opening the door it announces the station name and at the same time it displays a message of respective station name as shown in Fig (b). With the help of screen showing the passengers can easily identify the stations without confusion. While passengers entering the train, it detects how many passengers are entered through IR sensor and displays a number message in LCD screen as shown in the above Fig (c). From Fig (d) we can observe the message on LCD screen "DOOR CLOSED" it shows when the time limit gets over to enter passengers into the train. After the door movement it starts moving to the next station and the process repeats for every station in same mode.

Published By:

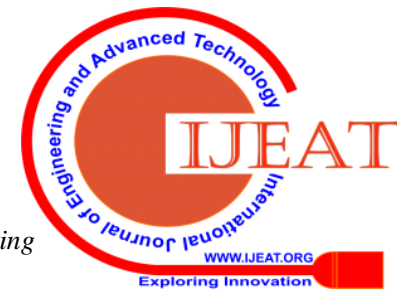




\section{CONCLUSION}

Hence, our model is implemented to run the train without driver within a specified time limit. By using this auto metro train, the arrival time of the train will be exact.

It also exhibits the messages on time at the respective station. Limits the passenger count and will avoid inconvenience caused to the passengers.

\section{REFERENCES}

1. V Arun,D.Laxma Reddy "Encryption standards for security system in energy harvesting for IoT requirements"Proceedings of the International Conference on Intelligent Sustainable Systems (ICISS 2017), IEEE Xplore, ISBN:978-1-5386-1959-9, pp.1224-1227.

2. SamreenJahan, E.Amareshwar"Raspberry pi based water quality monitoring and flood alerting system using iot", International Journal of Innovative Technology and Exploring Engineering, ISSN: 22783075, Volume-8 Issue-4S2 March, 2019, pp.237-240

3. K. Haribabu, Ch. Umasankar, "An Unmanned Soldier Assistance Vehicle with Autonomous Path Tracking", Journal of Advanced Research in Dynamical and Control Systems, Issue: 08-Special Issue, 2018, PP-1661-1664.

4. Mohan, Dinesh, "Mythologies, Metro Rail System and Future Urban Transport," in Proc. Economic \& Political Weekly, Jan. 2007, pp.4153.

5. Steven.F.Barrett, Daniel Pack, MitchellThornton, "Atmel AVR Microcontroller Primer: Programming and Interfacing," in Proc. Synthesis Lectures on Digital Circuits and Systems, vol 7, IJOART no. 2, Jun. 2012, pp. 167-243

6. M. P. Georgescu. Driverless CBTC - specific requirements for CBTC systems to overcome operation challenges. WIT Transactions on The Built Environment, Vol 88. 2008. pp. 401-409.

7. H. Yun, and K. Lee. Development of the Train Control System Data Transmission Technology Using a Wi-Fi Mesh. Proceeding if the ICTC 2011. Seoul . Sept 2011. Pp 406-410.

8. M. Siemiatycki. Message in a Metro: Building Urban Rail Infrastructure and Image in Delhi, India. International Journal of Urban and Regional Research, vol. 30, pp. 289-92

9. M. Verle. PIC Microcontrollers - Programming in C. mikroElektronika; 1st edition .2009.

\section{AUTHOR PROFILE:}

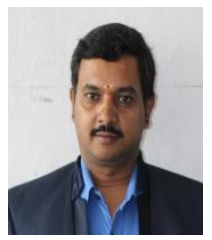

Dr. S.V.S Prasad, completed his B.Tech in Electronics and Communication Engineering, M.Tech in Computer \& Communication at JNTU Kakinada, Andhra Pradesh \& Ph.D at JNTU, Hyderabad His area of interestincludes Communication Systems and Image Processing. He has published more than 20 papers in International Journals and published 4 books in International Publishers. Currently he is working as a Professor \& Head of the Department of Electronics and Communication Engineering, MLR Institute of Technology, Hyderabad.

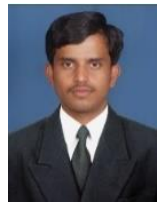

K Nishanth rao, Completed my B.Techin the year of 2010 in Electronics and Communication Engineering, completed my M.Techin the year of 2012 in RF \&am Microwave Engineering, Presently pursuing my Doctoral Degree in Antennasin DSU, Bangalore, India. My Interested Domains are Electromagnetic fields, Antennas and Communications.He has published more than 15 papers in various International Journals. 